American Journal of Applied Sciences 4 (6): 339-345, 2007

ISSN 1546-9239

(C) 2006 Science Publications

\title{
A Fuzzy-GAs Model for Determining Varied Irrigation Efficiency
}

\author{
${ }^{1}$ Anongrit Kangrang and ${ }^{2}$ Chavalit Chaleeraktrakoon \\ ${ }^{1}$ Faculty of Engineering, Mahasarakham University, Mahasarakham, Thailand \\ ${ }^{2}$ Department of Civil Engineering, Faculty of Engineering \\ Thammasat University, Klong Luang, Pathumthani, 12120, Thailand
}

\begin{abstract}
Irrigation efficiency is necessary information in water resource management. We proposed fuzzy sets approach for estimating varied irrigation efficiency. Genetic algorithms technique was applied to calibrate membership function of fuzzy model. The fuzzy sets technique considered the uncertainty of the available water resource and required area as the input variables. The approach model was applied to determine the fluctuated irrigation efficiency of the Nong Wei Irrigation Project (in the Northeast region of Thailand). Results found that the fuzzy-GAs model can be used to obtain the irrigation efficiencies, given the total available water resources and requested irrigation-area. The GAs calibration provided the optimal condition of the proposed model. Moreover, the proposed approach can be given the irrigation efficiencies which are close to the actual irrigation efficiency. Further, the results indicate that the varied irrigation efficiency is more precise than the constant irrigation efficiency.
\end{abstract}

Keywords : Fuzzy set, Genetic algorithms, Irrigation efficiency, Crop water-requirement

\section{INTRODUCTION}

Irrigation efficiency is important information in the planning of water resource management. Generally, the irrigation efficiency is the multiplication of conveyance, distribution and field application efficiencies. Often, most previous planning considered the irrigation efficiency as a constant value for all seasons ${ }^{[1-4]}$. However, it is likely that the efficiencies tend to vary due to the uncertainty of the water resources ${ }^{[5]}$. Therefore, they may use the erroneous irrigation efficiency which unsuitable for the seasonal available water.

A Fuzzy set is mathematical theory for describing the interested variables from uncertain factors or variables like seasonal inflows. The relationship between input and output variables is defined from fuzzy rule, according to human processes in thinking and decision. In addition, fuzzy rules are relatively easy to explain and understand. Recently, the fuzzy model was accepted to describe the relationship of the uncertain variables ${ }^{[6-10]}$. Often, the calibration processes of the fuzzy model were performed by manual adjusting (trial and error) the membership functions and rule bases. However, depending on the result of the adjustment, it does not guarantee to yield the optimal solution.
Genetic algorithms are search and optimization techniques based on the principles of national selection and genetics. GAs is a robust method for searching for the optimum solution of a complex problem. It can provide the near global optimal solution. The GA was applied to solve the optimal solution of water resource problems ${ }^{[1-14]}$. The best part of GA is that they can handle any type of objective function.

Often, at the starting of each irrigation season, the imploring areas for cultivation are required from a farmer, while the seasonal inflow is given from the reservoir administration which release for serving the scenario. However, this study guessed the factual irrigation efficiency should vary with available inflow that dependant on uncertainty of natural inflow and requested irrigation-area which change with the time.

This paper thus proposes the fuzzy set model for finding the varied irrigation efficiency which corresponding seasonal inflow and requested irrigationarea. The genetic algorithms technique is applied to calibrate the membership of the fuzzy model.

Model Formulation: In order to account for any uncertainty on seasonal inflow and requested irrigationarea, the fuzzy sets theory and its rule-based system are applied for estimating irrigation efficiency. System inputs include the seasonal inflow and the seasonal

Corresponding Author: Anongrit Kangrang, Lecturer, Faculty of Engineering, Mahasarakham University, Khamriang, Campus,Kantharawichai, Mahasarakham, 44150, Thailand 
requested area. Output is the seasonal irrigation efficiency. There are four steps in developing fuzzy model as the following.

The first step of creating a fuzzy model is to transform the crisp inputs into fuzzy variable through the membership function, called Fuzzification process. The number and type of membership functions are constructed based on statistical data and experience of engineers, generally upon the considering problem ${ }^{[15,}$ 16]. Because the seasonal irrigation efficiency and requested irrigation-area variables are high uncertainty, these trapezoidal, bell and sigmoid membership functions are unsuitable for describing them. Fuzzy sets with triangular and Gaussian membership functions are used to describe the uncertain parameters because of their flexibility and easy computation.

The second step, the fuzzy rule bases are created using seasonal historical data and fuzzy operator. The historical data of irrigation efficiency will be presented in the next section. These fuzzy operators AND and OR are applied to combine the input variables.

Next step is to apply the input membership functions and the rule bases to obtain the output membership functions. This step is done by the implication method which obtaining a fuzzy set of output when given a single number of each inputs. Then the output membership functions of each rule are jointed to one output fuzzy set, called aggregation process.

Finally, the process is defuzzification that a fuzzy set of output is converted into a single crisp value. The most common defuzzification method is the "centroid" evaluation, which returns the center of area under the curve.

The adequacy of the fuzzy model is evaluated by considering the coefficient of determination $\left(\mathrm{R}^{2}\right)$ which defined based on the irrigation efficiency estimation errors as:

$$
\mathrm{R}^{2}=\frac{\left(\sum \phi_{j} \hat{\phi}_{j}-m \overline{\phi_{j}} \overline{\hat{\phi}}_{j}\right)^{2}}{\left(\sum \phi_{j}{ }^{2}-m \bar{\phi}_{j}^{2}\right)\left(\sum \hat{\phi}_{j}^{2}-m \overline{\hat{\phi}}_{j}^{2}\right)}
$$

where $\phi_{j}$ is the estimated irrigation efficiency of the scenario during season $j$ which calculated using fuzzy model, $\hat{\phi}_{j}$ is the actual irrigation efficiency of the scenario during season $j$ which calculated from irrigated area, $\overline{\phi_{j}}$ and $\overline{\hat{\phi}_{j}}$ are respectively the average of above mentions and $m$ is the number of yearly data. The fuzzy model is calibrated by adjusting the membership functions and rule bases using the genetic algorithms technique, these performances will be stopped when the results obtained the highest coefficient of determination (closed to 1.0).

The calibration processes using GAs are described as follows. GAs requires encoding schemes that transform the decision variables into chromosome. Then, the genetic operations (reproduction, crossover, and mutation) are performed. These genetic operations will generate new sets of chromosomes. In this study, each decision variable represents a parameter of membership function. The objective function of the search is to maximize the coefficient of determination $\left(\mathrm{R}^{2}\right)$. This study used population size $=80$, crossover probability $=0.9$, and mutation probability $=0.01$.

Generally, an irrigation efficiency is the overall system efficiency which affecting by conveyance, distribution and field application ${ }^{[1-4,17]}$. The irrigation efficiency of the system can be computed for each scenario by the following equation:

$$
\hat{\phi}=100\left(\frac{V r}{V d}\right)
$$

where $V r$ is the net volume of crop water requirement, and $V d$ is the amount of water diverted from the source to the conveyance system.

The net volume of crop water requirement is computed by the method developed as:

$$
V r=\sum_{k=1}^{K}\left(E P_{k} \times K C_{k}\right) X_{k}
$$

where $E P_{k}$ is potential evaporation, $K C_{k}$ is crop coefficient, and $X_{k}$ is cultivated area of crop $k$.

Illustrative Application: Three sequences of 26-year (1978 - 2003) seasonal flow, irrigated area and crop water-requirement records; and related evaporation, and effective rainfall data (the Nong Wei Irrigation Project in the Northeast region of Thailand) during dry season were considered for illustrating the application of the proposed approach. Figure 1 presents the location of the Nong Wei Irrigation Project. 


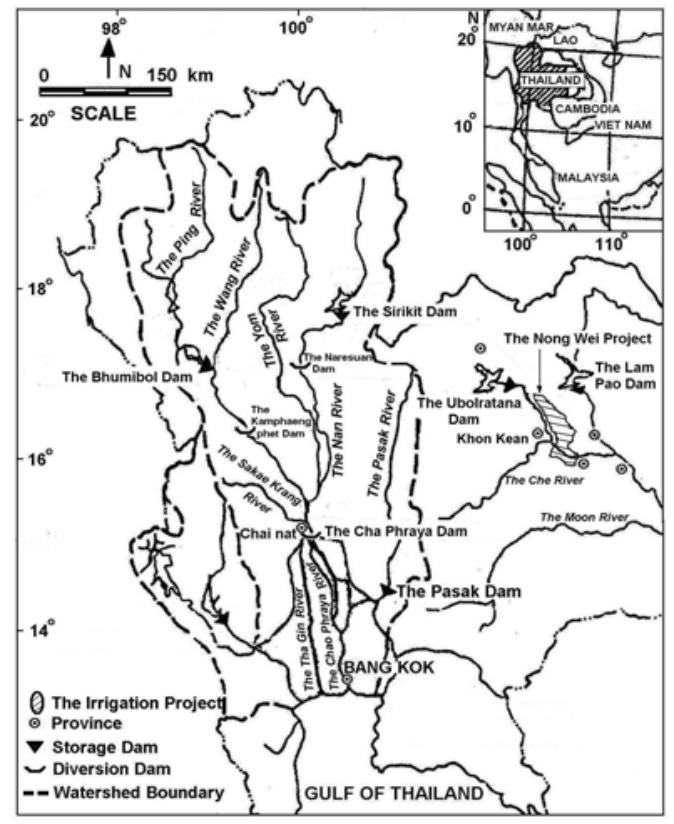

Fig. 1: Locations of the Nong Wei Irrigation Project

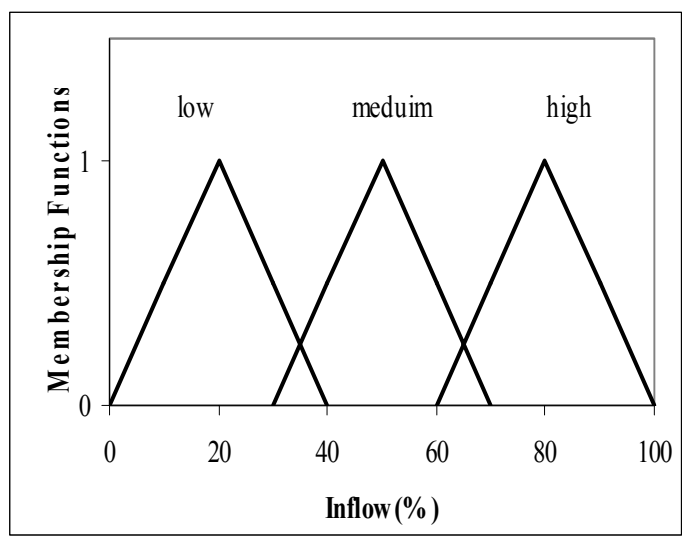

(a)

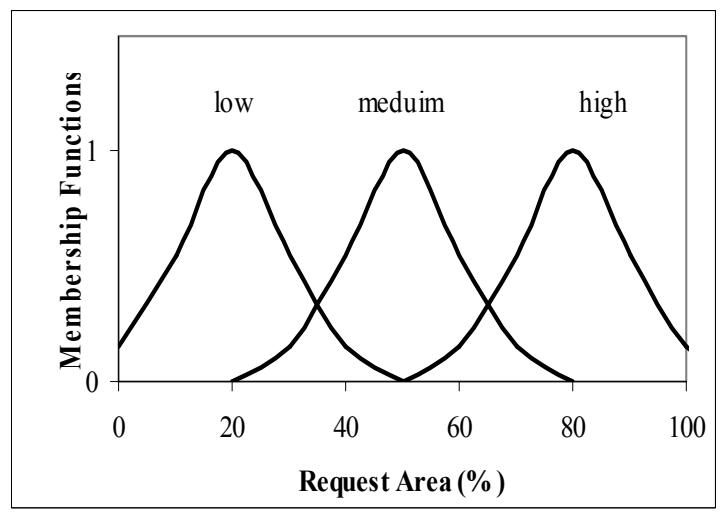

(b)

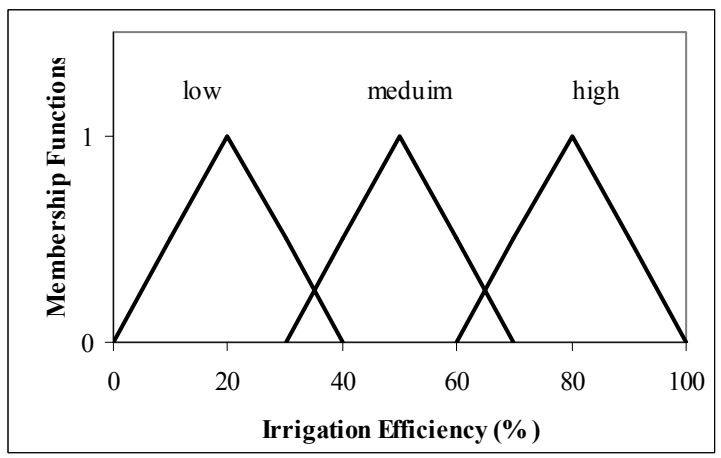

(c)

Fig. 2: Typical membership functions of input and output variables using triangular and Gaussian types

Table 1 gives the available inflow, requested irrigationarea and the irrigation efficiency during dry season for 26 years. The results indicate that the maximum and the minimum seasonal inflow are $521 \mathrm{MCM}$ and $51 \mathrm{MCM}$ respectively. The seasonal requested irrigation-areas are varying during 10,100 and 230,100 Rai ( $1 \mathrm{Rai}=1,600$ $\mathrm{m}^{2}$ ). Note that, the seasonal irrigation efficiency in $1983,1988,1996$, and 1997 are greater than $100 \%$, so the data of these years are not accepted to compute. Table 2 shows an example of fuzzy rule bases using AND and OR operators. The numbers of membership function of each variable are 2, 3 and 4 that cover the preliminary cluster of the historical data. Figure 2 shows the typical membership functions of the input and output variables using triangular and Gaussian type.

\section{RESULTS AND DISCUSSIONS}

Tables 3 and 4 show the coefficient of determination for several membership functions using the manual adjustment and the GAs calibration. The results shown that the coefficients of determination of GAs calibration are higher than those of manual adjustment, the highest values are 0.9887 and 0.9925 using number $4-4-3$ of triangular and Gaussian respectively. These results found that the suitable number and shape of membership functions give the highest coefficient of determination; the GAs calibration provided the optimal condition of membership function. The function was further validated using the actual irrigation efficiencies which were not considered (1979, 1986, 1987, 1998, and 2001) for constructing model. 
Am. J. Applied Sci., 4 (6): 339-345, 2007

Table 1: Historical data of an available inflow, requested irrigation-area and the irrigation efficiency

\begin{tabular}{|c|c|c|c|c|c|c|c|}
\hline \multirow[t]{2}{*}{ Year } & \multirow{2}{*}{$\begin{array}{l}\text { Inflow } \\
\text { (MCM) }\end{array}$} & \multirow{2}{*}{$\begin{array}{c}\text { Requested } \\
\text { irrigation-area } \\
\text { (Rai) }\end{array}$} & \multicolumn{4}{|c|}{ Irrigated area (Rai) } & \multirow{2}{*}{$\begin{array}{c}\text { Irrigation } \\
\text { efficiency } \\
(\%)\end{array}$} \\
\hline & & & Rice & Corn & Vegetable & Total & \\
\hline 1978 & 51 & 10,100 & 6,294 & 1,767 & 963 & 9,024 & 29.19 \\
\hline $1979 *$ & 63 & 25,900 & 16,746 & 2,066 & 1,551 & 20,363 & 34.64 \\
\hline 1980 & 177 & 22,000 & 20,726 & 1,207 & 1,122 & 23,055 & 23.39 \\
\hline 1981 & 120 & 33,500 & 28,260 & 2,227 & 2,173 & 32,660 & 48.31 \\
\hline 1982 & 185 & 14,210 & 14,762 & 96 & 284 & 15,142 & 15.20 \\
\hline 1983 & 70 & 70,100 & 64,691 & 662 & 1,557 & 66,910 & $176.72 * *$ \\
\hline 1984 & 226 & 64,120 & 54,931 & 1,376 & 1,886 & 58,193 & 47.14 \\
\hline 1985 & 226 & 27,110 & 25,788 & 869 & 1,116 & 27,773 & 22.40 \\
\hline $1986^{*}$ & 112 & 58,500 & 48,169 & 4,867 & 3,478 & 56,514 & 51.96 \\
\hline $1987^{*}$ & 241 & 33,440 & 25,917 & 5,729 & 3,142 & 34,788 & 35.00 \\
\hline 1988 & 188 & 120,620 & 98,747 & 11,428 & 4,606 & 114,781 & $110.04 * *$ \\
\hline 1989 & 441 & 172,800 & 154,450 & 13,726 & 2,407 & 170,583 & 70.73 \\
\hline 1990 & 500 & 212,020 & 181,820 & 28,175 & 1,268 & 211,263 & 75.89 \\
\hline 1991 & 521 & 221,150 & 186,950 & 17,658 & 1,886 & 206,494 & 72.18 \\
\hline 1992 & 496 & 230,100 & 209,066 & 12,694 & 1,660 & 223,420 & 83.21 \\
\hline 1993 & 479 & 151,230 & 117,430 & 20,085 & 1,313 & 138,828 & 52.15 \\
\hline 1994 & 377 & 43,290 & 27,900 & 15,012 & 1,200 & 44,112 & 19.83 \\
\hline 1995 & 350 & 110,540 & 57,250 & 30,834 & 2,600 & 90,684 & 44.25 \\
\hline 1996 & 118 & 101,120 & 68,315 & 28,083 & 1,968 & 98,366 & $147.83 * *$ \\
\hline 1997 & 275 & 150,080 & 125,355 & 21,180 & 1,509 & 148,044 & $100.13^{* *}$ \\
\hline $1998^{*}$ & 381 & 105,300 & 78,972 & 16,572 & 1,917 & 97,461 & 57.47 \\
\hline 1999 & 218 & 112,250 & 89,318 & 13,925 & 2,883 & 106,126 & 91.01 \\
\hline 2000 & 452 & 151,552 & 150,567 & 3,354 & 1,893 & 155,814 & 66.49 \\
\hline $2001^{*}$ & 486 & 172,624 & 176,205 & 2,080 & 1,379 & 179,664 & 71.63 \\
\hline 2002 & 488 & 165,000 & 152,772 & 4,591 & 2,493 & 159,856 & 63.06 \\
\hline 2003 & 467 & 204,400 & 198,172 & 2,502 & 2,637 & 203,311 & 83.71 \\
\hline
\end{tabular}

Table 2: Example of fuzzy rule bases for estimating irrigation efficiency

\begin{tabular}{|c|c|c|}
\hline $\begin{array}{c}\text { IF } \\
\text { Inflow }\end{array}$ & $\begin{array}{l}\text { AND } \\
\text { Requested } \\
\text { irrigation-area }\end{array}$ & $\begin{array}{l}\text { THEN } \\
\text { Irrigation efficiency }\end{array}$ \\
\hline less & $\begin{array}{l}\text { less } \\
\text { medium } \\
\text { high }\end{array}$ & $\begin{array}{l}\text { medium } \\
\text { medium } \\
\text { high }\end{array}$ \\
\hline medium & $\begin{array}{l}\text { less } \\
\text { medium } \\
\text { high }\end{array}$ & $\begin{array}{l}\text { less } \\
\text { medium } \\
\text { medium }\end{array}$ \\
\hline high & $\begin{array}{l}\text { less } \\
\text { medium } \\
\text { high }\end{array}$ & $\begin{array}{l}\text { less } \\
\text { less } \\
\text { medium }\end{array}$ \\
\hline
\end{tabular}

Tables 5 and 6 show the deviations between the estimated irrigation efficiency and the actual efficiency, as well as the deviations between the estimated irrigation efficiency and the constant efficiency of
Triangular and Gaussian membership function respectively. The results show that the former deviations are less than those of the second. In addition, the estimated irrigation efficiencies are close to the actual efficiency. Moreover, the averaged deviations between the fuzzy and actual efficiencies of triangular and Gaussian membership functions are 2.98 $\%$ and $2.44 \%$ respectively. The deviations are quite small, as compared with those of the constant efficiency. It indicates that the varied irrigation efficiency is more precise than the constant irrigation efficiency. For this reason, the calibrated Gaussian membership function of 4-4-3 is accepted to find the varying irrigation efficiency. Figure 3 shows the calibrated Gaussian membership functions of the input and output variables for the number 4-4-3 using GAs technique. 
Am. J. Applied Sci., 4 (6): 339-345, 2007

Table 3: Membership function numbers of requested irrigation-area, inflow, and irrigation efficiency with $\mathrm{R}^{2}$ for Triangular membership function

\begin{tabular}{|c|c|c|c|c|c|c|c|c|c|}
\hline \multicolumn{3}{|c|}{ Number of membership function } & \multicolumn{2}{|c|}{$\mathrm{R}^{2}$} & \multicolumn{3}{|c|}{ Number of membership function } & \multicolumn{2}{|c|}{$\mathrm{R}^{2}$} \\
\hline $\begin{array}{l}\text { Request } \\
\text { area }\end{array}$ & Inflow & $\begin{array}{l}\text { Irrigation } \\
\text { efficiency }\end{array}$ & $\begin{array}{c}\text { GAs } \\
\text { calibration }\end{array}$ & $\begin{array}{c}\text { Manual } \\
\text { adjustment }\end{array}$ & $\begin{array}{c}\text { Request } \\
\text { area }\end{array}$ & Inflow & $\begin{array}{l}\text { Irrigation } \\
\text { efficiency }\end{array}$ & $\begin{array}{c}\text { GAs } \\
\text { calibration }\end{array}$ & $\begin{array}{c}\text { Manual } \\
\text { adjustment }\end{array}$ \\
\hline 4 & 4 & 4 & 0.9712 & 0.9094 & 3 & 3 & 2 & 0.7775 & 0.7057 \\
\hline 4 & 4 & 3 & $0.9887 *$ & 0.9167 & 3 & 2 & 4 & 0.8726 & 0.8006 \\
\hline 4 & 4 & 2 & 0.8452 & 0.6855 & 3 & 2 & 3 & 0.6979 & 0.6259 \\
\hline 4 & 3 & 4 & 0.8859 & 0.8239 & 3 & 2 & 2 & 0.6994 & 0.6274 \\
\hline 4 & 3 & 3 & 0.9136 & 0.8516 & 2 & 4 & 4 & 0.8741 & 0.8021 \\
\hline 4 & 3 & 2 & 0.8674 & 0.8054 & 2 & 4 & 3 & 0.863 & 0.7910 \\
\hline 4 & 2 & 4 & 0.8002 & 0.7382 & 2 & 4 & 2 & 0.6834 & 0.6124 \\
\hline 4 & 2 & 3 & 0.6934 & 0.6314 & 2 & 3 & 4 & 0.823 & 0.7511 \\
\hline 4 & 2 & 2 & 0.8123 & 0.6395 & 2 & 3 & 3 & 0.8248 & 0.7528 \\
\hline 3 & 4 & 4 & 0.8645 & 0.8025 & 2 & 3 & 2 & 0.8013 & 0.7293 \\
\hline 3 & 4 & 3 & 0.9094 & 0.8474 & 2 & 2 & 4 & 0.7015 & 0.6293 \\
\hline 3 & 4 & 2 & 0.8214 & 0.7591 & 2 & 2 & 3 & 0.6932 & 0.6213 \\
\hline 3 & 3 & 4 & 0.8543 & 0.7933 & 2 & 2 & 2 & 0.7341 & 0.6621 \\
\hline 3 & 3 & 3 & 0.8019 & 0.7142 & & & & & \\
\hline
\end{tabular}

Table 4: Membership function numbers of requested irrigation-area, inflow, and irrigation efficiency with $\mathrm{R}^{2}$ for Gaussian membership function

\begin{tabular}{|c|c|c|c|c|c|c|c|c|c|}
\hline \multicolumn{3}{|c|}{ Number of membership function } & \multicolumn{2}{|c|}{$\mathrm{R}^{2}$} & \multicolumn{3}{|c|}{ Number of membership function } & \multicolumn{2}{|c|}{$\mathrm{R}^{2}$} \\
\hline $\begin{array}{l}\text { Request } \\
\text { area }\end{array}$ & Inflow & $\begin{array}{l}\text { Irrigation } \\
\text { efficiency }\end{array}$ & $\begin{array}{c}\text { GAs } \\
\text { calibration }\end{array}$ & $\begin{array}{c}\text { Manual } \\
\text { adjustment }\end{array}$ & $\begin{array}{c}\text { Request } \\
\text { area }\end{array}$ & Inflow & $\begin{array}{l}\text { Irrigation } \\
\text { efficiency }\end{array}$ & $\begin{array}{c}\text { GAs } \\
\text { calibration }\end{array}$ & $\begin{array}{c}\text { Manual } \\
\text { adjustment }\end{array}$ \\
\hline 4 & 4 & 4 & 0.9818 & 0.9098 & 3 & 3 & 2 & 0.7671 & 0.6951 \\
\hline 4 & 4 & 3 & $0.9925^{*}$ & 0.9205 & 3 & 2 & 4 & 0.7721 & 0.7001 \\
\hline 4 & 4 & 2 & 0.7767 & 0.7047 & 3 & 2 & 3 & 0.7538 & 0.6818 \\
\hline 4 & 3 & 4 & 0.8794 & 0.8074 & 3 & 2 & 2 & 0.7269 & 0.6549 \\
\hline 4 & 3 & 3 & 0.966 & 0.8940 & 2 & 4 & 4 & 0.8766 & 0.8046 \\
\hline 4 & 3 & 2 & 0.9067 & 0.8347 & 2 & 4 & 3 & 0.8477 & 0.7757 \\
\hline 4 & 2 & 4 & 0.7943 & 0.7223 & 2 & 4 & 2 & 0.7556 & 0.6836 \\
\hline 4 & 2 & 3 & 0.7215 & 0.6495 & 2 & 3 & 4 & 0.813 & 0.7410 \\
\hline 4 & 2 & 2 & 0.7424 & 0.6704 & 2 & 3 & 3 & 0.7988 & 0.7268 \\
\hline 3 & 4 & 4 & 0.8838 & 0.8118 & 2 & 3 & 2 & 0.7833 & 0.7113 \\
\hline 3 & 4 & 3 & 0.9338 & 0.8618 & 2 & 2 & 4 & 0.7509 & 0.6789 \\
\hline 3 & 4 & 2 & 0.8124 & 0.7380 & 2 & 2 & 3 & 0.8124 & 0.6267 \\
\hline 3 & 3 & 4 & 0.8717 & 0.7997 & 2 & 2 & 2 & 0.7066 & 0.6346 \\
\hline 3 & 3 & 3 & 0.8023 & 0.7303 & & & & & \\
\hline
\end{tabular}


Table 5: Deviation between the estimated irrigation efficiency and the actual efficiency, as well as the deviation between the estimated irrigation efficiency and the constant efficiency (Triangular, 4-3-3)

\begin{tabular}{|c|c|c|c|c|c|c|}
\hline \multirow[b]{2}{*}{ Year } & \multirow{2}{*}{$\begin{array}{l}\text { Inflow } \\
\text { (MCM) }\end{array}$} & \multirow{2}{*}{$\begin{array}{c}\text { Requested } \\
\text { irrigation-area } \\
\text { (Rai) }\end{array}$} & \multicolumn{2}{|c|}{ Irrigation efficiency (\%) } & \multirow{2}{*}{$\left|\hat{\phi}_{j}-\phi_{j}\right|$} & \multirow{2}{*}{$\mid \hat{\phi}_{j}-\phi$} \\
\hline & & & $\hat{\phi}_{j}$ (Actual) & $\phi_{j}$ (Estimated) & & \\
\hline 1979 & 63.445 & 25,900 & 34.64 & 29.68 & 4.96 & 22.06 \\
\hline 1986 & 112.334 & 58,500 & 51.96 & 48.65 & 3.31 & 4.74 \\
\hline 1987 & 241.435 & 33,440 & 35.00 & 36.08 & 1.08 & 21.70 \\
\hline 1998 & 381.324 & 105,300 & 57.47 & 54.54 & 2.93 & 0.77 \\
\hline 2001 & 486.020 & 172,624 & 71.63 & 74.23 & 2.60 & 14.93 \\
\hline
\end{tabular}

Table 6: Deviation between the estimated irrigation efficiency and the actual efficiency, as well as the deviation between the estimated irrigation efficiency and the constant efficiency (Gaussian, 4-3-3)

\begin{tabular}{|c|c|c|c|c|c|c|}
\hline \multirow{2}{*}{ Year } & \multirow{2}{*}{$\begin{array}{l}\text { Inflow } \\
(\mathrm{MCM})\end{array}$} & \multirow{2}{*}{$\begin{array}{c}\text { Requested } \\
\text { irrigation-area } \\
\text { (Rai) }\end{array}$} & \multicolumn{2}{|c|}{ Irrigation efficiency (\%) } & \multirow{2}{*}{$\left|\hat{\phi}_{j}-\phi_{j}\right|$} & \multirow{2}{*}{$\left|\hat{\phi}_{j}-\phi\right|$} \\
\hline & & & $\hat{\phi}_{j}$ (Actual) & $\phi_{j}$ (Estimated) & & \\
\hline 1979 & 63.445 & 25,900 & 34.64 & 31.14 & 3.50 & 22.06 \\
\hline 1986 & 112.334 & 58,500 & 51.96 & 48.78 & 3.18 & 4.74 \\
\hline 1987 & 241.435 & 33,440 & 35.00 & 34.69 & 0.31 & 21.70 \\
\hline 1998 & 381.324 & 105,300 & 57.47 & 54.72 & 2.75 & 0.77 \\
\hline 2001 & 486.020 & 172,624 & 71.63 & 74.10 & 2.47 & 14.93 \\
\hline
\end{tabular}

Figure 4 presents the relationship between the input variables (seasonal inflow and requested area) and the out put variable (irrigation efficiency) for the number 44-3 of Gaussian membership functions. It shows that at the low inflow with low requested area provides the less irrigation efficiency, while at the high inflow with the high requested area gives the high irrigation efficiency. Also, it indicates that available water on the high inflow situation is enough for the project and the farmer can be cultivated fully land area, so the irrigation efficiency is increased.

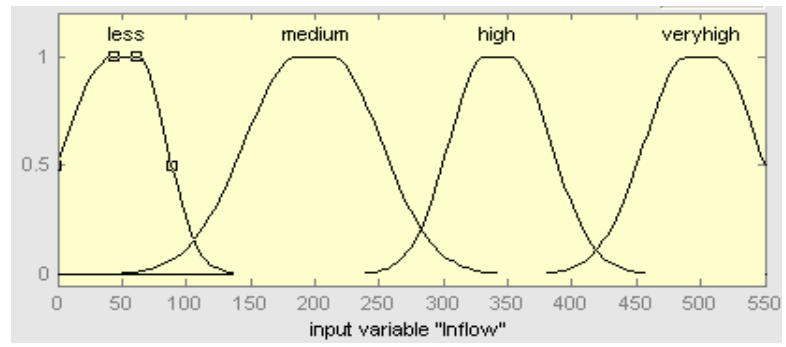

(a)

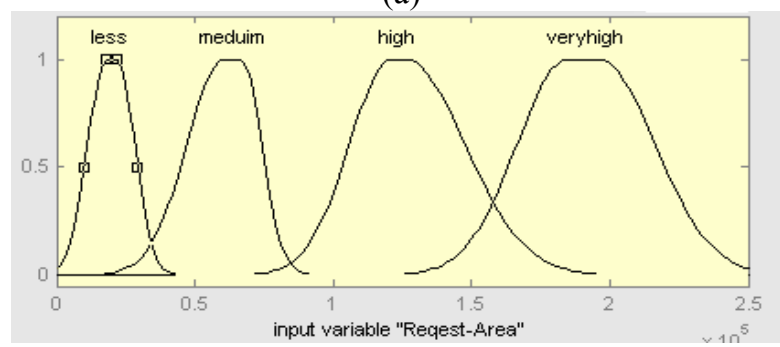

(b)

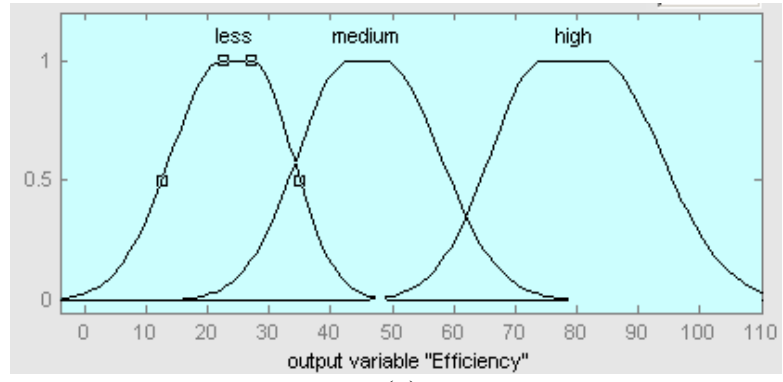

(c)

Fig. 3: The calibrated Gaussian membership functions of the input and output variables for the number 4-4-3

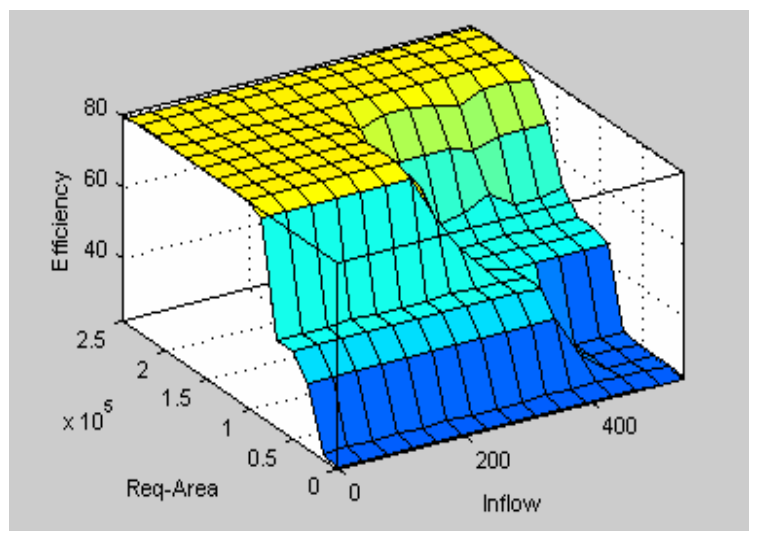

Fig 4: Relationship between the input variables and the out put variable of Gaussian membership function number 4-4-3 


\section{CONCLUSIONS}

This paper developed a fuzzy set for finding the varied irrigation efficiency. The calibration process of the fuzzy model used Genetic algorithms technique. Results show that the fuzzy sets theory which used in this study can be used to estimate the varied irrigation efficiencies, given the total available water resources and requested irrigation-areas which are uncertain variables. The Genetic algorithms calibration of the model provided the optimal condition of membership function. The deviations between the estimated irrigation efficiency and the actual efficiency are quite small, as compared with the deviations between the estimated irrigation efficiency and the constant efficiency. In addition, the estimated irrigation efficiencies are close to the actual efficiency. It indicates that the varied irrigation efficiency is more precise than the constant irrigation efficiency.

\section{ACKNOWLEDGE}

The authors would like to express their appreciation to Faculty of Engineering, Mahasarakham University for financial support.

\section{REFERENCES}

1. Brown, D., 1999. Water-use efficiency on irrigation systems: a review of research carried out under DFID's engineering research program. Agricultural Water Management, 40, 139-147.

2. Ali, M. H., Shui, L. T., Yan, K. C., Eloubaidy, A. F. and Foong, K. C., 2000. Modeling water balance components and irrigation efficiencies in relation to water requirements for double-cropping systems. Agricultural Water Management, 46, 167-182.

3. Yoshida, K., Tanji, H., Somura, H., Toda, O. And Higuchi K., 2004. Evaluation of irrigation efficiency at KM6 Project site, LAOS. Proceedings of $2^{\text {nd }}$ Asia Pacific Association of Hydrology and Water Resources Conference, 5-8 July, 2004 Singapore, volume I, 652-659.

4. Royal Irrigation Department, RID, 2004. The plain for allocating water in dry season 2004/2005 of the Nong Wei Irrigation Project, Royal Irrigation Department, Report. (in Thai)

5. Burke, S. Mulligan, M. and Thornes, J. B., 1999. Optimal irrigation efficiency for maximum plant productivity and minimum water loss. Agricultural Water Management, 40, 377-391.
6. Ross, T. J., 1995. Fuzzy logic with engineering application. McGraw-Hill Inc., USA.

7. Shrestha, B.P., Duckstein, L. and Stakhiv, E.Z., 1996. Fuzzy rule based modeling of reservoir operation. Journal of Water Resources Planning and Management, 122(4), 262-269.

8. Jairaj, P. G. and Vedula, S., 2000. Multireservoir system optimization using fuzzy mathematical programming. Water Resources Management, 14(6), 457-472

9. Panigrahi, D. P. and Mujumda, P. P., 2000. Research operation modeling with fuzzy logic. Water Resources Management, 14, 89-109.

10. Umamahesh, N. V. and Chandramouli, S., 2004. Fuzzy dynamic programming model for optimal operation of a multipurpose reservoir. Proceedings of $2^{\text {nd }}$ Asia Pacific Association of Hydrology and Water Resources Conference, 5-8 July, 2004 Singapore, volume I, 164-171.

11 Wardlaw, R. and Sharif, M., 1999. Evaluation of Genetic Algorithms for Optimal Reservoir System Operation. Journal of Water Resources Planning and Management, ASCE, 124(1): 25-33.

12 Goldberg, D.E., 1989. Genetic Algorithms in Search, Optimization, and Machine Learning, Addison-Wesley Publishing Company Inc., London. $412 \mathrm{p}$.

13 Chang, F. J., Lai, J. S. and Kao, L. S., 2003. Optimization of operation rule curves and flushing schedule in a reservoir. Hydrological Processes, 17: 1623-1640.

14 Kangrang, A. and Chaleeraktrakoon, C., 2007. Genetic Algorithms Connected Simulation with Smoothing Function for Searching Rule Curves. American Journal of Applied Sciences, 4(2): 7379.

15. Jang, S. R., Sun, C. T. and Mizutani, E., 1997. Neuro-Fuzzy and soft computing. Prentice-Hall Inc., USA.

16. Saruwatari, N. and Yomota, A., 1995. Forecasting system of irrigation water on paddy field by fuzzy theory. Agricultural Water Management, 28, 163-167.

17. Ali, M. H. and Shui, L. T., 2001. Optimal allocation of monthly water withdrawals in reservoir systems. Water Resources Management, 15, 323-341. 